\title{
Gastrointestinal Stromal Tumor: Clinicopathological Features, Management, and Comparison of Three Risk Stratification Schemes
}

\author{
Wedad B. Hashem ${ }^{1}$, Tamer H. El-Nahas ${ }^{1}$, Marine Fawzy ${ }^{1}$, Shady $\mathrm{N}$. \\ Mashhour ${ }^{2}$, Mohamed H. Zedan ${ }^{3}$, Karim N. Mashhour ${ }^{1}$
}

1 Kasr Al-Ainy Center of Clinical Oncology and Nuclear Medicine, Kasr Al-Ainy School of Medicine, Cairo University, Cairo, Egypt; ${ }^{2}$ Radiology Department, Kasr Al-Ainy School of Medicine, Cairo University, Cairo, Egypt; ${ }^{3}$ Surgical Oncology Department, National Cancer Institute, Cairo University, Cairo, Egypt

\begin{abstract}
Background: Gastrointestinal stromal tumor (GIST) is the most common mesenchymal neoplasm of the gastrointestinal tract. To optimize its management, different risk stratification schemes had been developed for GIST. Aim: To describe the clinicopathological profile and management of GIST and to evaluate three different GIST risk stratification schemes.

Methods: Retrospective review of patients treated in a single Egyptian center during an 11-year period. High-risk GIST was identified using three different risk stratification schemes; the Armed Forces Institute of Pathology (AFIP) scheme, the National Institute of Health (NIH) consensus scheme and the American Joint Committee on Cancer (AJCC) TNM staging system.

Results: The disease extent at the presentation of 34 patients was localized in 19 (56\%), locally advanced in 4 (12\%) and metastatic in 11 (32\%). Twenty-one (62\%) underwent surgery and achieved complete remission. Their median overall survival was not reached. The median disease-free survival (DFS) was 58.2 months (95\%CI: 28.8 - 58.2) and the 3 -year rate was $66 \%$. Non-gastric GIST, larger tumors $(>10 \mathrm{~cm}$ ) and high mitotic index ( $>5 / 50 \mathrm{HPF}$ ) was associated with shorter DFS ( $p=0.146,0.047$ and 0.06, respectively). The AFIP, NIH consensus and AJCC TNM risk stratification methods identified high-risk groups that had a significantly shorter median DFS than lower-risk groups ( $p=0.022$, 0.009 and 0.22 , respectively).

Conclusion: All the studied three risk stratification schemes categorized a high-risk group with significantly poorer outcome. According to the information available, any of these schemes may be used in identifying high-risk GIST.
\end{abstract}

Keywords: Gastrointestinal stromal tumor, Risk stratification, Management, Prognosis

Corresponding author: Karim N. Mashhour, MD; Kasr Al-Ainy Center of Clinical Oncology and Nuclear Medicine, Kasr Al-Ainy School of Medicine, Cairo University, Cairo, 11553, Egypt; E-mail: karim.mashhour.81@gmail.com

Submitted: 25-August-2020, Finally revised: 22-December-2020, Accepted: 10-January-2021, Published online: 16-April-2021

\section{Introduction}

Gastrointestinal stromal tumor (GIST) is the most common mesenchymal neoplasm of the gastrointestinal tract. It may occur at any age with a peak incidence at the age of 60 years and both genders are usually equally affected ${ }^{1}$.

Most (95\%) of GISTs positively express for KIT (CD117). Around $80 \%$ of GISTs show a mutation in the gene that encodes the KIT receptor tyrosine kinase, while $5-10 \%$ of GISTs show a mutation in the gene related to the platelet-derived growth factor receptor alpha (PDGFRA) receptor tyrosine kinase ${ }^{2}$. Approximately 10 - 15\% of GISTs are wildtype showing no mutations in the KIT or PDGFR that mandate further evaluation ${ }^{3}$.

The mitotic index (number of mitosis per 50 high power fields [HPF]) as well as the size of the primary tumor has a strong prognostic significance. The best prognosis is seen in $<5 \mathrm{~cm}$ tumors (maximum dimension) with a mitosis $<5 / 50$ HPFs. Gastric GISTs have proven to be of the best 
prognosis compared to other primary sites ${ }^{4}$.

Surgical intervention is considered the primary treatment modality for patients having either localized or potentially resectable tumors ${ }^{5}$.

Imatinib is a tyrosine kinase inhibitor (TKI) that selectively inhibits KIT protein tyrosine kinase, BCR-ABL, and PDGFRA. It was approved in the adjuvant setting for resectable GIST, as well as in the palliative setting for unresectable/metastatic tumors. In the postoperative adjuvant setting, imatinib (400 mg/day) is recommended for highrisk patients for a period of at least 36 months ${ }^{6}$. Preoperative neoadjuvant imatinib may be used for 6 to 12 months in unresectable tumors either due to large sizes or technically difficult surgical cases ${ }^{7}$.

Sunitinib is a multi-targeted TKI with an antivascular endothelial growth factor receptor (VEGFR) activity, which is recommended in cases with imatinib resistance ${ }^{8}$. Regorafenib, a multikinase inhibitor, was approved in the treatment of GIST after failure of imatinib and sunitinib ${ }^{9}$. Other agents such as pazopanib, dasatinib, and nilotinib have now been incorporated in the treatment algorithm of GIST ${ }^{10}$.

A number of risk stratification schemes had been developed to identify high-risk GIST that needs more intensive treatment 4, 11-13. The identification of high-risk GIST patients is important for tailoring the treatment following resection of localized GIST 7 .

The aim of this study was to describe the clinicopathological pattern, management and outcome of GIST in a single Egyptian center and to compare the predictive ability of three GIST risk stratification schemes in our setting.

\section{Methods}

This retrospective study included patients with GIST who had been treated at Kasr Al-Aini Center of Clinical Oncology and Nuclear Medicine, Kasr AlAiny School of Medicine, Cairo University during an 11-year period, from November-2005 to November2016.

\section{Patients and management}

The files of all patients with confirmed GIST diagnosis were reviewed to retrieve the following data:

- Demographic data: age, sex, performance status, smoking history and co-morbidities.

- Disease characteristics: site, size, mitotic index and immunohistochemistry. The diagnosis of GIST was confirmed by positive immunohistochemistry for CKIT, PDGFR, DOG1 or CD34.

- Radiological investigations:

- Baseline: computerized tomography scans (chest, abdomen and pelvis) \pm dedicate magnetic resonance imaging.

- Treatment assessment: done with the same primary modality of radiological investigation every 3 months.

- During the surveillance period: done every 3 months in the first 2 years, then every 6 months until the end of the $5^{\text {th }}$ year.

- Treatment details:

- Surgery: curative or palliative intent.

- Tyrosine kinase inhibitors: as neoadjuvant (for locally advanced tumors before surgery), adjuvant (for high-risk patients after curative surgery, imatinib $400 \mathrm{mg} /$ day for 3 years) or palliative (for metastatic patients, imatinib $400 \mathrm{mg}$ / day initially then $800 \mathrm{mg} \mathrm{/} \mathrm{day} \mathrm{upon}$ progression or shifting to $2^{\text {nd }}$ line sunitinib).

- Treatment response assessment according to the Response Evaluation Criteria in Solid Tumors (RECIST)

\section{Risk stratification schemes}

Patients were risk-stratified using three methods; the Armed Forces Institute of Pathology (AFIP) stratification scheme which was developed by Miettinen and Lasota ${ }^{11}$, National Institute of Health (NIH) consensus risk scheme ${ }^{4}$, and the American Joint Committee on Cancer (AJCC) TNM staging system ${ }^{13}$. Both the AFIP and NIH consensus schemes are applicable only to non-metastatic GIST.

The AFIP scheme depends on the tumor site, tumor size and mitotic index. Because not all sites were identified in the AFIP scheme and for the purpose of this study, omental tumors were categorized as gastric while mesenteric, retroperitoneal and colonic sites as jejunal/ileal. The AFIP scheme stratified risk into none, very low, low, moderate and high.

The NIH consensus scheme classifies GIST according to the size and the mitotic index into very low-, low-, intermediate- and high-risk groups.

The AJCC TNM staging system for GIST is based on the mitotic index, tumor size, tumor site, lymph node metastases and distant metastases. There is an AJCC TNM staging system for GIST of the stomach or the omentum and another one for GIST of the 
small intestine, esophagus, colon, rectum or peritoneum. Non-metastatic GIST is stratified into stages I, II and III (A/B) according to the AJCC TNM staging system.

\section{Statistical analysis}

Data were described in terms of the mean and standard deviation, median and range or frequencies and percentages when appropriate. Kaplan-Meier method was used for survival analysis. Overall survival (OS) was calculated from the date of pathological diagnosis to the date of death. Disease-free survival was calculated from the date of surgery to the date of relapse or death. Log-rank test was used to test the significance of difference in survival. A $p$ value $<0.05$ was considered significant.

Statistical analysis was done using the IBM Statistical Package for the Social Science (SPSS) Statistics for Windows, Version 22.0. Armonk, NY: IBM Corp.

\section{Results}

During the 10-year period of the study, 67 patients with GIST were managed at our center. Thirty-four (51\%) patients with complete data were included in the following analysis.

Patients' demographics and disease characteristics are illustrated in Table 1. Their median age was 55 years (range: 28-79) and the encountered comorbidities were diabetes mellitus (4, 11.8\%), hypertension (4, 11.8\%), cardiac disease $(3,8.8 \%)$, and others $(4,11.8 \%)$. The diagnostic modality was computerized tomography in $22(64.7 \%)$ patients, endoscopy in $9(26.4 \%)$ and others in $3(8.9 \%)$. The median tumor size was $10 \mathrm{~cm}$ (range: $3-28$ ) and the mean was $12.4 \mathrm{~cm} \pm 7.6 \mathrm{~cm}$.

Table 2 illustrates the immunohistochemical markers done. The majority (82\%) of the patients had a C-KIT positive tumor. In the 6 patients with negative/not done CKIT, the diagnosis of GIST was confirmed by the positivity of PDGFR or DOG1.
Table 1: Patient and tumor characteristics $(n=34)$

\begin{tabular}{|c|c|c|}
\hline \multirow{2}{*}{ Characteristic } & & Description \\
\hline & & Mean (SD) \\
\hline \multirow[t]{2}{*}{ Age } & & $53.7(13.8)$ \\
\hline & & $n(\%)$ \\
\hline \multirow[t]{2}{*}{ Sex } & Male & $14(41.2)$ \\
\hline & Female & $20(58.8)$ \\
\hline \multirow[t]{3}{*}{ Smoking } & No & $25(73.5)$ \\
\hline & Yes & $4(11.8)$ \\
\hline & Unknown & $5(14.7)$ \\
\hline \multirow[t]{3}{*}{ Comorbidities } & No & $21(61.8)$ \\
\hline & Yes & $11(32.4)$ \\
\hline & Unknown & $2(5.9)$ \\
\hline \multirow[t]{4}{*}{ ECOG performance } & 0 & $4(11.8)$ \\
\hline & 1 & $23(67.6)$ \\
\hline & 2 & $5(14.7)$ \\
\hline & 3 & $2(5.9)$ \\
\hline \multirow[t]{8}{*}{ Primary tumor site } & Stomach & $13(38.2)$ \\
\hline & Small intestine & 9 (26.5) \\
\hline & Colon & $3(8.8)$ \\
\hline & Mesentery & $3(8.8)$ \\
\hline & Retroperitoneum & $3(8.8)$ \\
\hline & $\begin{array}{l}\text { Hepatic focal } \\
\text { lesion }\end{array}$ & $1(2.9)$ \\
\hline & Rectum & $1(2.9)$ \\
\hline & Lesser omentum & $1(2.9)$ \\
\hline \multirow[t]{4}{*}{ Tumor size } & $\leq 5$ & $5(14.7)$ \\
\hline & $>5-\leq 10$ & $10(29.4)$ \\
\hline & $>10$ & $12(35.3)$ \\
\hline & Unknown & $7(20.6)$ \\
\hline \multirow{3}{*}{$\begin{array}{l}\text { Disease extent at } \\
\text { diagnosis }\end{array}$} & Localized & $19(55.9)$ \\
\hline & $\begin{array}{l}\text { Locally } \\
\text { advanced }\end{array}$ & $4(11.8)$ \\
\hline & Metastatic & 11 (32.4) \\
\hline \multirow[t]{5}{*}{ Site of metastasis } & Liver & $8(23.5)$ \\
\hline & Lung & $2(5.9)$ \\
\hline & Mediastinum & $1(2.9)$ \\
\hline & Paraaortic & $1(2.9)$ \\
\hline & Peritoneum & $1(2.9)$ \\
\hline \multirow{4}{*}{$\begin{array}{l}\text { Histopathological } \\
\text { type }\end{array}$} & Spindle cell & $27(79.4)$ \\
\hline & Mixed & $2(5.9)$ \\
\hline & Undifferentiated & $1(2.9)$ \\
\hline & Unknown & $4(11.8)$ \\
\hline \multirow[t]{3}{*}{ Mitotic index } & $\leq 5 / 50 \mathrm{HPF}$ & $18(52.9)$ \\
\hline & $>5 / 50 \mathrm{HPF}$ & $4(11.8)$ \\
\hline & Unknown & $12(35.3)$ \\
\hline
\end{tabular}

ECOG: Eastern Cooperative Oncology Group, SD: Standard deviation 
Table 2: Immuno-histochemical markers done in 34 patients with GIST

\begin{tabular}{llll}
\hline Marker & Positive & Negative & Not done \\
\cline { 2 - 4 } & $n(\%)$ & $n(\%)$ & $n(\%)$ \\
\hline C KIT & $28(82.4)$ & $4(11.8)$ & $2(5.9)$ \\
\hline CD 34 & $14(41.2)$ & $3(8.8)$ & $17(50)$ \\
\hline S 100 & $2(5.9)$ & $11(32.4)$ & $21(61.8)$ \\
\hline Desmin & $1(2.9)$ & $7(20.6)$ & $26(76.5)$ \\
\hline SMA & $3(8.8)$ & $2(5.9)$ & $29(85.3)$ \\
\hline DOG1 & $4(11.8)$ & 0 & $30(88.2)$ \\
\hline PDGFR & $2(5.9)$ & 0 & $32(94.1)$ \\
\hline Vimentin & $1(2.9)$ & $1(2.9)$ & $32(94.1)$
\end{tabular}

The management of patients is summarized in Figure 1. Two patients with locally-advanced disease received neoadjuvant imatinib $400 \mathrm{mg}$ daily. One of them with a rectal primary achieved adequate tumor response, which was followed by sphincter sparing R0 resection then adjuvant imatinib for 2 years. Later, this patient developed distant metastasis for which imatinib was restarted. The other patient with a gastric primary died 5 months after starting treatment due to a cardiac cause.

Among the 21 patients who achieved complete remission (CR), 16 patients received adjuvant imatinib $400 \mathrm{mg}$ daily for a mean duration of 14.9 months $(\mathrm{SD}=9.4)$.

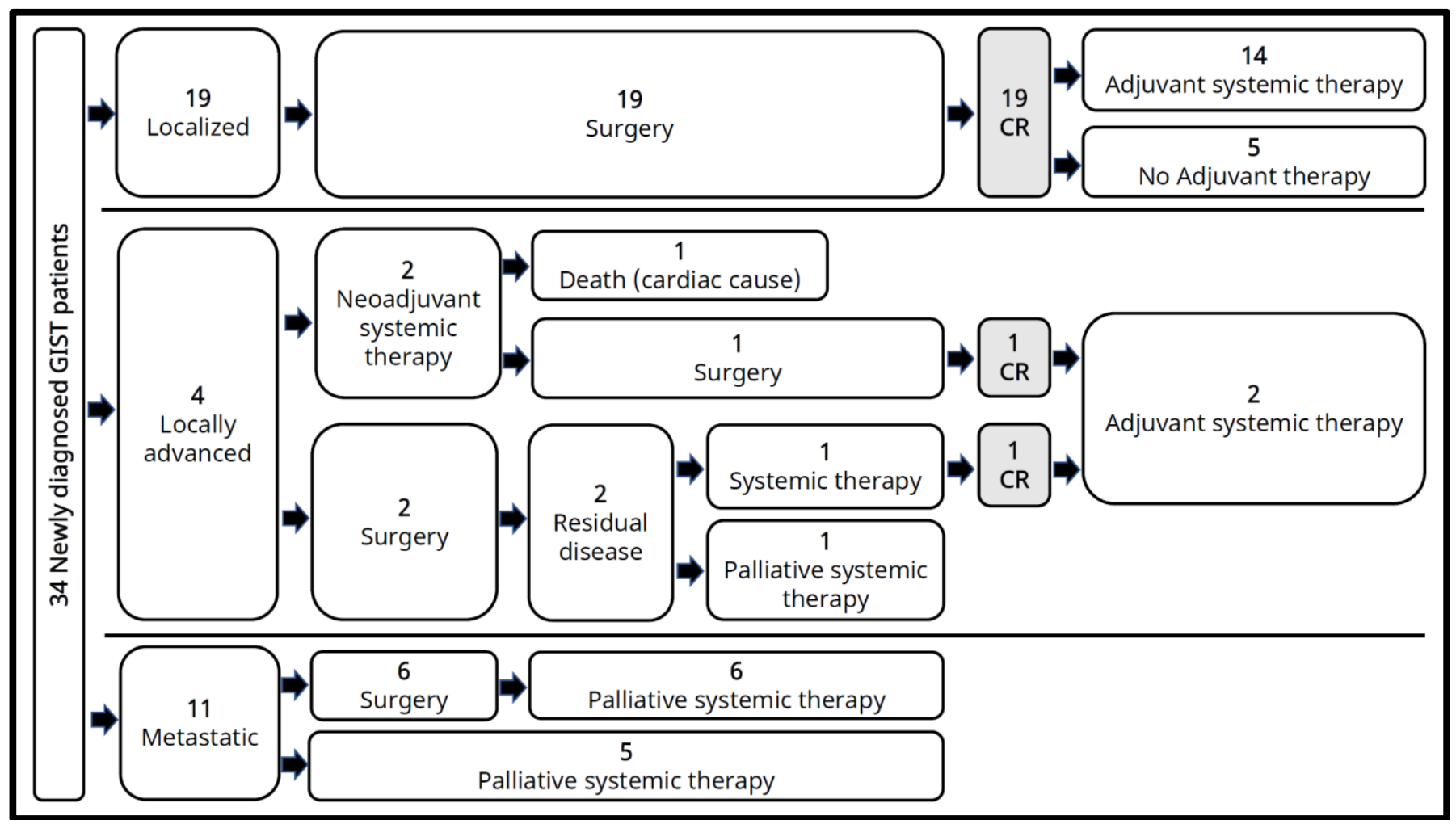

Figure 1: Summary of the management of 34 patients with GIST in different stages

Patients were followed up for a median duration of 38.9 months (95\%CI: 32.9 - 56.8). The mean overall survival of the whole group of patients was 84.5 months (95\%CI: 67.2 - 101.8) and the median was not reached. The median OS for patients with localized disease was not reached and for those with locally advanced/metastatic disease it was 37.1 months (95\%CI: $13.9-37.1)(p=0.0314$, Figure 2).

The risk stratification of patients who achieved CR according to the three studied stratification schemes is shown in Table 3.

The median os survival of patients who achieved CR was not reached and the mean was 72 months (95\%CI: 62.3 - 81.7).

The median DFS of the 21 patients who achieved CR was 58.2 months (95\%CI: 28.8 - 58.2) and their 3year DFS rate was $65.7 \%$. Among these patients, the three studied risk stratification methods identified a high-risk group with significantly worse median DFS (Table 4, Figures 3 - 5). Patients with gastric GIST had a longer median DFS than those with nongastric GIST (58.2 months [95\%CI: $28.4-58.2$ ] vs. 33.8 [95\%CI: $18.9-33.8$ ], $p=0.146$ ). Also, patients with $\leq 10 \mathrm{~cm}$ tumors had a better median DFS than those with $>10 \mathrm{~cm}$ tumors (58.2 months [95\%CI: 22.4 -58.2] vs. 47.1 [95\%CI: not reached], $p=0.0467$ ). 


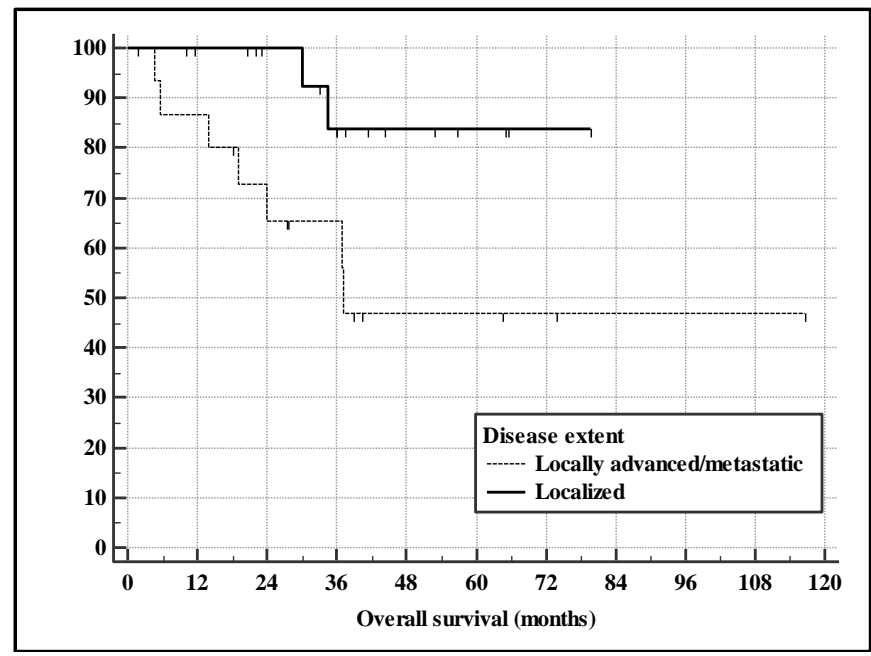

Figure 2: Kaplan-Meier overall survival curves according to the extent of disease at presentation

Table 3: Risk stratification of 21 patients with nonmetastatic GIST who achieved complete remission

\begin{tabular}{lll}
\hline Risk stratification & Risk & $n(\%)$ \\
\hline AFIP scheme & & $0(0)$ \\
\cline { 2 - 3 } & None & $1(4.8)$ \\
\cline { 2 - 3 } & Low low & $6(28.6)$ \\
\cline { 2 - 3 } & Moderate & $4(19)$ \\
\cline { 2 - 3 } & High & $7(33.3)$ \\
\cline { 2 - 3 } NIH consensus scheme & Unknown & $3(14.3)$ \\
& Very low & $0(0 \%)$ \\
\cline { 2 - 3 } & Low & $2(9.5)$ \\
\cline { 2 - 3 } & Intermediate & $9(42.9)$ \\
\cline { 2 - 3 } & High & $8(38.1)$ \\
\cline { 2 - 3 } & Unknown & $2(9.5)$ \\
\hline AJCC TNM staging system & Stage I & $7(33.3)$ \\
\cline { 2 - 3 } & Stage II & $4(19)$ \\
\cline { 2 - 3 } & Stage III & $7(33.3)$ \\
\cline { 2 - 3 } & Unknown & $3(14.3)$ \\
\hline
\end{tabular}

AFIP: Armed Forces Institute of Pathology, AJCC: American Joint Committee on Cancer, HPF: High-power fields, NIH: National Institute of Health, SD: Standard deviation

From the 21 patients who achieved CR; the site of relapse was distant in 3, local in 1 and both in 1 . These relapsed 5 cases received imatinib $400 \mathrm{mg}$ daily for a median duration of 10 months. One patient underwent surgery (exploration and resection anastomosis) with postoperative residual disease and had a stationary course on imatinib for 4 years. Gastric signet-ring carcinoma was diagnosed in 1 patient 28 months after surgery for gastric GIST.
Table 4: DFS of high-risk groups compared to other risk categories using 3 risk stratification schemes

\begin{tabular}{|c|c|c|c|}
\hline $\begin{array}{l}\text { Risk stratification } \\
\text { scheme }\end{array}$ & $n$ & $\begin{array}{l}\text { Median DFS in } \\
\text { months }(95 \% \mathrm{CI})\end{array}$ & $\begin{array}{l}p \\
\text { value }\end{array}$ \\
\hline \multicolumn{4}{|l|}{ AFIP scheme } \\
\hline $\begin{array}{l}\text { Low / moderate- } \\
\text { risk }\end{array}$ & 11 & $58.2(58.2-58.2)$ & \multirow[t]{2}{*}{0.0224} \\
\hline High-risk & 7 & $33.8(18.9-33.8)$ & \\
\hline \multicolumn{4}{|l|}{ NIH scheme } \\
\hline $\begin{array}{l}\text { Low / } \\
\text { intermediate-risk }\end{array}$ & 11 & $58.2(58.2-58.2)$ & \multirow[t]{2}{*}{0.0091} \\
\hline High-risk & 8 & 47.1 (not reached) & \\
\hline \multicolumn{4}{|l|}{ AJCC stage } \\
\hline Stage I / II & 11 & $58.2(58.2-58.2)$ & \multirow[t]{2}{*}{0.0224} \\
\hline Stage III & 7 & $33.8(18.9-33.8)$ & \\
\hline
\end{tabular}

AFIP: Armed Forces Institute of Pathology, AJCC: American Joint Committee on Cancer, CI: Confidence interval, HPF: High-power fields, NIH: National Institute of Health

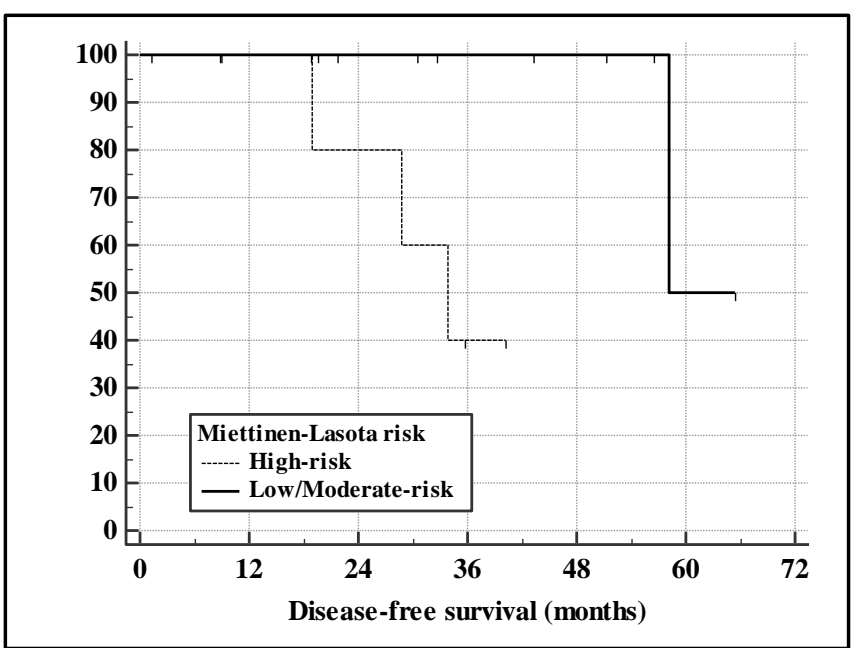

Figure 3: Kaplan-Meier disease-free survival curves according to the Armed Forces Institute of Pathology (AFIP) risk stratification

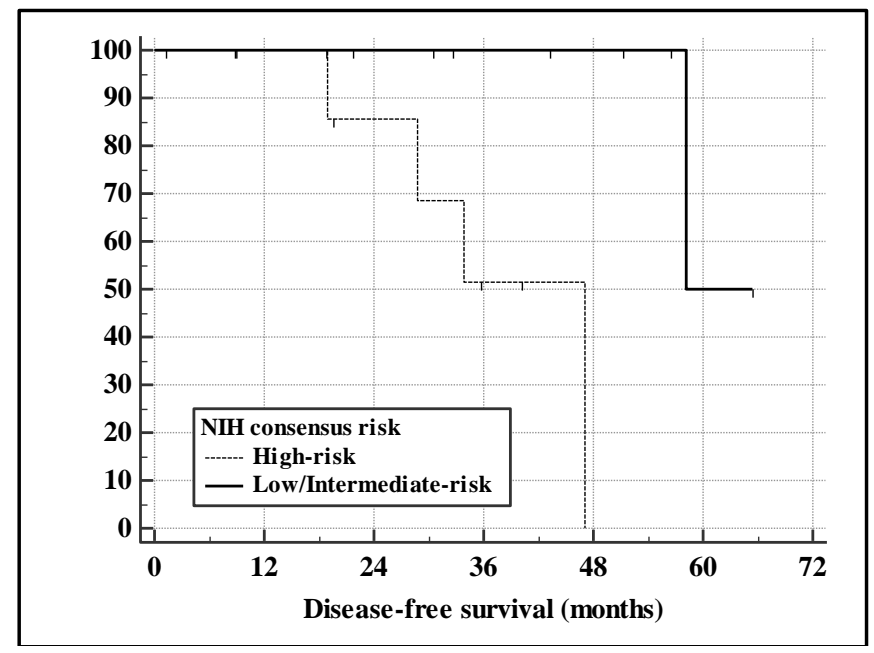

Figure 4: Kaplan-Meier disease-free survival curves according to the National Institute of Health (NIH) consensus risk stratification 


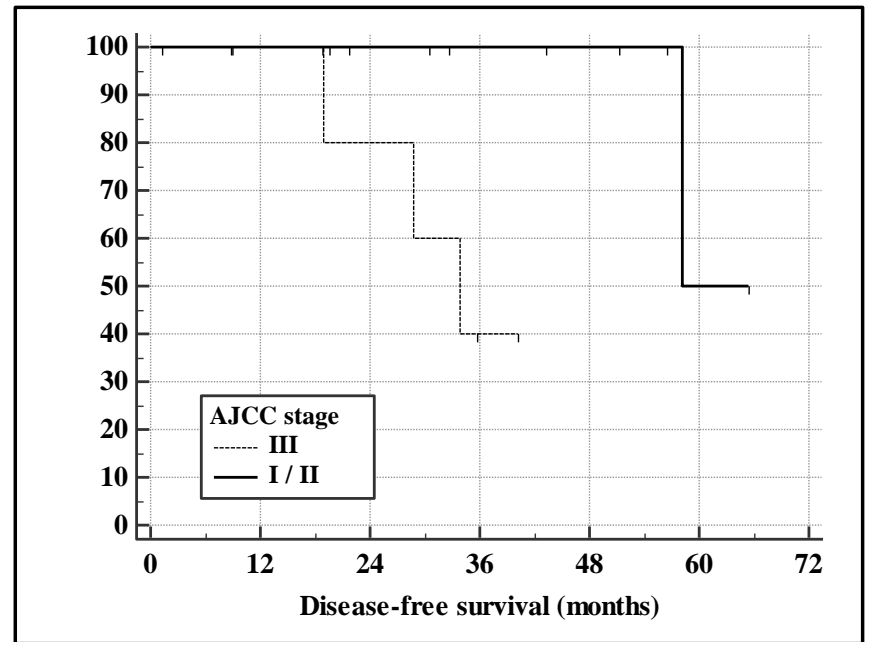

Figure 5: Kaplan-Meier disease-free survival curves according to the American Joint Committee on Cancer (AJCC) staging system

\section{Discussion}

This study described the clinicopathological pattern and management of GIST in a single Egyptian center and compared three GIST risk stratification schemes.

The clinicopathological characteristics of patients included in this report are alomst similar to that reported in the literature with some variations which may be attributed to the small sample size. Globally, the median age at diagnosis of GIST is in the mid-60s ${ }^{1}$. The median age of 54 years in this study is lower than that reported globally. Similarly, other studies from Egypt reported a younger age at GIST presentation in the mid-50s ${ }^{14,15}$. There is no clear explanation for this finding. We noticed that the majority of the cases had spindle cell GIST. A finding similar to that found in other studies ${ }^{16,17}$.

Using the three risk stratification schemes under study, about one-third of our patients were classified as high risk. This is similar to the finding of Søreidea et al ${ }^{1}$ in their systematic review that analyzed GIST epidemiological data from around the globe.

Previous studies have compared different GIST risk stratification methods ${ }^{18-21}$. Some of these studies found no difference in the predictive ability of commonly used risk stratification methods and others suggested the superiority of one of them. Goh et al ${ }^{18}$ compared the NIH, Hunag-modified NIH and AFIP systems and concluded that all of them are useful with supreriotiry of the AFIP system in predicting the prognosis of primary localized GIST. Using data on GIST patients in the Surveillance,
Epidemiology and End Results database, Oweira et al ${ }^{19}$ compared the NIH, AFIP and AJCC systems and found that the three systems are comparable in predicting cancer-specific survival in GIST. Zhao et al ${ }^{20}$ conducted a similar study using GIST data of the Surveillance, Epidemiology and End Results database and compared the same three stratification systems; however, their findings were different. They concluded that the AJCC system is superior to the NIH and AFIP ones in predicting progonsis of GIST regardless of the tumor site. Another more recent study assessed the survival prediction ability of the NIH, AFIP and AJCC systems in gastric GIST and found that the three systems are comparable ${ }^{21}$.

The results of this study support the findings of previous ones comparing the NIH, AFIP and AJCC systems in that the three systems are comparable in predicitng GIST prognosis.

This study has a number of limitations. It is a single center retrospective one that included a small sample size. Moreover, in view of the better prognosis of GIST patients than other solid malignancies, the follow-up duration was relatively short. The lack of patient adherence to follow up visits was a major limitation encountered in our study. Performing adequate immunohistochemical studies was not possible in some patients due to fragmented DNA specimens. We did not compare the modified NIH consensus stratification method because of the lack of operative details about tumor rupture, which is among the factors considered in this method [12].

\section{Conclusion}

In our setting, GIST is uncommon and surgery was the cornerstone in the management of patients with localized disease the AFIP, NIH consensus and AJCC TNM systems determined a high-risk group with a significantly worse DFS.

\footnotetext{
Acknowledgment

None.

\section{Authors' contribution}

Conception or design: WBH, THE, MF, SNM, MHZ \& KNM; Acquisition, analysis or interpretation of data: WBH, MF, SNM \& KNM; Drafting the manuscript: WBH, MHZ \& KNM; Revising the manuscript: THE, MF \& SNM; Approval of the manuscript version to be published: All authors; Agreement to be accountable for all aspects of the work: All authors.

\section{Conflict of interest}

The authors declare that they have no conflict of interest to disclose.
} 


\section{Data a vailability}

Deidentified individual participant data used to produce the results of this study are available from the corresponding author (KNM) upon request.

\section{Ethical considerations}

The study was approved by the Research Committee of Kasr Al-Ainy Center of Clinical Oncology and Nuclear Medicine, Kasr Al-Ainy School of Medicine, Cairo University.

\section{Funding}

The authors did not receive funding for this study.

\section{Study registration}

None.

\section{References}

1. Søreide K, Sandvik OM, Søreide JA, Giljaca V, Jureckova A, Bulusu VR. Global epidemiology of gastrointestinal stromal tumours (GIST): A systematic review of population-based cohort studies. Cancer Epidemiol. 2016; 40: 39-46.

2. Corless CL, Barnett CM, Heinrich MC. Gastrointestinal stromal tumours: Origin and molecular oncology. Nat Rev Cancer. 2011; 11(12): 865-878.

3. Kays JK, Sohn JD, Kim BJ, Goze K, Koniaris LG. Approach to wild-type gastrointestinal stromal tumors. Transl Gastroenterol and Hepatol. 2018; 3: 92.

4. Fletcher CD, Berman JJ, Corless C, et al. Diagnosis of gastrointestinal stromal tumors: A consensus approach. Hum Pathol. 2002; 33(5): 459-465.

5. Demetri GD, von Mehren M, Antonescu CR, et al. NCCN Task Force report: update on the management of patients with gastrointestinal stromal tumors. J Natl Compr Canc Netw. 2010; 8 (Suppl 2): S1-41.

6. Joensuu H, Eriksson M, Sundby Hall K, et al. One vs Three Years of Adjuvant Imatinib for Operable Gastrointestinal Stromal Tumor. JAMA. 2012; 307(12): 1265-1272.

7. Casali PG, Abecassis N, Aro HT, et al. Gastrointestinal stromal tumours: ESMO-EURACAN Clinical Practice Guidelines for diagnosis, treatment and follow-up. Ann Oncol. 2018; 29(Suppl 4): iv68-iv78.

8. Demetri GD, van Oosterom AT, Garrett CR, et al. Efficacy and safety of sunitinib in patients with advanced gastrointestinal stromal tumour after failure of imatinib: a randomised controlled trial. Lancet. 2006: 368(9544): 1329-1338.

9. Demetri GD, Reichardt P, Kang YK, et al. Efficacy and safety of regorafenib for advanced gastrointestinal stromal tumours after failure of imatinib and sunitinib (GRID): an international, multicentre, randomised, placebo-controlled, phase 3 trial. Lancet. 2013; 381(9863): 295-302.

10. Vallilas C, Sarantis P, Kyriazoglou A, et al
Gastrointestinal Stromal Tumors (GISTs): Novel Therapeutic Strategies with Immunotherapy and Small Molecules. Int J Mol Sci. 2021; 22(2): 493.

11. Miettinen M, Lasota J. Gastrointestinal stromal tumors: pathology and prognosis at different sites. Semin Diagn Pathol. 2006; 23(2): 70-83.

12. Joensuu H. Risk stratification of patients diagnosed with gastrointestinal stromal tumor. Human pathology. 2008; 39(10): 1411-1419.

13. American Joint Committee on Cancer. Gastrointestinal Stromal Tumor. In: AJCC Cancer Staging Manual. 8th ed. New York, NY: Springer; 2017: 523-529.

14. Al-Kalaawy M, El-Zohairy MA, Mostafa A, AlKalaawy A, El-Sebae H. Gastrointestinal stromal tumors (GISTs), 10-year experience: patterns of failure and prognostic factors for survival of 127 patients. J Egypt Natl Canc Inst. 2012; 24(1): 31-39.

15. Kassem MI, Elzeiny MM, Elhaddad HM. Management of gastrointestinal stromal tumors: a prospective and retrospective study. Egypt J Surg. 2016; 35(1): 1119.

16. Bhalgami R, Manish K, Patil P, Mehta S, Mohandas KM. Clinicopathological study of 113 gastrointestinal stromal tumors. Indian J Gastroenterol. 2013; 32(1): 22-27.

17. Jumniensuk C, Charoenpitakchai M. Gastrointestinal stromal tumor: Clinicopathological characteristics and pathologic prognostic analysis. World J Surg Oncol. 2018; 16(1): 231.

18. Goh BK, Chow PK, Yap WM, et al. Which is the optimal risk stratification system for surgically treated localized primary GIST? Comparison of three contemporary prognostic criteria in 171 tumors and a proposal for a modified Armed Forces Institute of Pathology risk criteria. Ann Surg Oncol. 2008; 15(8): 2153-2163.

19. Oweira H, Schmidt J, Mehrabi A, Kulaksiz H, Schneider P, Schöb O, Giryes A, Abdel-Rahman O. Comparison of three prognostic models for predicting cancer-specific survival among patients with gastrointestinal stromal tumors. Future Oncology. 2018 Feb;14(4):379-89.

20. Zhao B, Zhang J, Mei D, Zhang J, Luo R, Xu H, Huang B. The assessment of different risk classification systems for gastrointestinal stromal tumors (GISTs): the analytic results from the SEER database. Scandinavian journal of gastroenterology. 2018 Nov 2;53(10-11):1319-27.

21. Di Vita M, Zanghì A, Cavallaro A, Cardì F, Uhlig M, Ursi P, Menzo EL, Panebianco V, Cappellani A. Gastric GIST and prognostic models. Which is the best to predict survival after surgery?. Annali italiani di chirurgia. 2019 Jan 1;90:31-40. 